\title{
Molecular interactions between amine and cyclic ketones at different temperatures
}

\author{
M. G. Sankar • V. Ponneri • K. S. Kumar • \\ Sivarambabu Sakamuri
}

Received: 8 January 2013/Accepted: 24 June 2013/Published online: 27 October 2013

(C) The Author(s) 2013. This article is published with open access at Springerlink.com

\begin{abstract}
Measurement of densities $\rho$, viscosities $\eta$, and ultrasonic speeds $u$ has been carried out for binary mixtures of $N, N$-diethylaniline ( $N, N$-DEA) with acetophenone, cyclopentanone, cyclohexanone $(\mathrm{CH})$, and 2-methylcyclohexanone $(\mathrm{Me}-\mathrm{CH})$ and their pure liquids at (303.15 and 308.15) $\mathrm{K}$. These experimental data have been used to calculate the excess molar volume $V^{\mathrm{E}}$, deviation in ultrasonic velocity $\Delta u$, deviation in isentropic compressibility $\Delta \kappa_{s}$, and deviation in viscosity $\Delta \eta$. The variation of these properties with composition of the mixtures suggests dipole-dipole interactions and charge-transfer complex formation between $N, N$-diethylaniline and dipolar ketones. The magnitude of the property is found to depend on the chain length of the ketones' molecule. The viscosity data have been correlated using three equations: Grunberg and Nissan (Nature 164:799-800, 1949), Katti and Chaudhri (J Chem Eng Data 9:442-443, 1964), and Hind et al. (Trans Faraday Soc 56:328-330, 1960). These results have been fitted to the Redlich-Kister polynomial using multiparametric nonlinear regression analysis to estimate the binary coefficients and standard errors.
\end{abstract}

M. G. Sankar

Department of Chemistry, J.K.C. College, Guntur 522006, India

V. Ponneri

Department of Chemistry, S.V. University, Tirupathi 517502, India

\section{K. S. Kumar}

Department of Chemistry, S.V. Arts U.G. \& P.G. College

(T.T.D’S), Tirupathi 517502, India

S. Sakamuri $(\bowtie)$

Acharya Nagarjuna University, Guntur 522510, AP, India

e-mail: sivarambabu99@gmail.com
Keywords $\quad N, N$-diethylaniline - Cyclic ketones · Ultrasonic speed · Viscosity · Density · Excess thermodynamic parameters

\section{Introduction}

The interaction between solvents with polar groups and the carbonyl group of ketones plays a role in the structural effects, molecular level, and practical applications. The chemical industries have recognized the importance of the thermodynamic properties in design calculations involving chemical separations, heat transfer, mass transfer, and fluid flow. When two or more solvent molecules are associated with one another to form a liquid mixture, it brings about a marked effect on the properties of the resulting system and differences in the intermolecular interactions of the solvents. This fact is well known as the transport phenomenon and thermo-physical properties of mixed solvents. The present study is a continuation of our earlier research [1-4] on thermodynamic properties of binary liquid mixtures. The liquids were chosen in the present investigation on the basis of their industrial importance. $N, N$-diethylaniline is used as a solvent, in the preparation of dyes, and in various organic products. The carbonyl group is a part of several biologically important molecules such as proteins, lipids, and hormones. Ketones are a class of chemical compounds containing the carbonyl group in which the carbon atom is covalently bonded to an oxygen atom. Ketones are important intermediates in the synthesis of many organic compounds such as alkoxides, hydroxyalkynes, phosphine oxides, and cyanohydrins. Among the various ketones, acetophenone is used to create fragrances that resemble jasmine. It is used in chewing gum. Ketones are chosen in the present investigations since they find a variety of 
Table 1 Comparison of the experimental and literature values of density $(\rho)$, ultrasonic sound velocity $(u)$, and viscosity $(\eta)$ for pure components at $298.15 \mathrm{~K}$

\begin{tabular}{|c|c|c|c|c|c|c|}
\hline \multirow[t]{2}{*}{ Pure components } & \multicolumn{2}{|c|}{ Density $\rho / \mathrm{g} \mathrm{cm}^{-3}$} & \multicolumn{2}{|c|}{ Velocity $u / \mathrm{m} \mathrm{s}^{-1}$} & \multicolumn{2}{|c|}{ Viscosity $\eta / \mathrm{mPa} . \mathrm{s}$} \\
\hline & Experimental & Literature & Experimental & Literature & Experimental & Literature \\
\hline$N, N$-diethylaniline & 0.92992 & $0.92990^{\mathrm{a}}$ & 1411.0 & $1434 *^{\mathrm{b}}$ & 1.917 & $1.9191^{\mathrm{a}}$ \\
\hline Acetophenone & 1.02359 & $1.02360^{\mathrm{c}}$ & 1475.0 & $1476.2^{\mathrm{e}}$ & 1.673 & $1.674^{\mathrm{c}}$ \\
\hline Cyclopentanone & 0.94319 & $0.94320^{\mathrm{c}}$ & 1375.0 & $1374 *^{\mathrm{f}}$ & 1.082 & $1.084^{\mathrm{c}}$ \\
\hline Cyclohexanone & 0.94109 & $0.94110^{\mathrm{c}}$ & 1388.0 & $1388^{\mathrm{f}}$ & 2.013 & $2.011^{\mathrm{c}}$ \\
\hline 2-Methylcyclohexanone & 0.92083 & $0.92085^{\mathrm{d}}$ & 1346.0 & $1346^{* \mathrm{f}}$ & 2.225 & \\
\hline
\end{tabular}

* $303.15 \mathrm{~K}$

${ }^{a}$ Ref. [17]

${ }^{b}$ Ref. [18]

c Ref. [19]

d Ref. [7]

${ }^{\text {e Ref. [20] }}$

${ }^{f}$ Ref. [22]

applications such as solvent, lacquers, oils, resins, etc. The carbonyl group can interact with basic groups like the amino group to form a complex and influence the properties of such compounds.

In recent years, several studies have been advanced to study thermodynamic and transport properties of binary liquid mixtures containing ketones [5-15]. A perusal of the literature reveals that the thermo-physical property studies on the binary mixtures containing $N, N$-diethylaniline are not yet reported. This paper presents the data on density, viscosity, and speed of sound measurements in a system of $\mathrm{N}, \mathrm{N}$-diethylaniline with four ketones at (303.15 and 308.15) K. Using these experimental data, excess molar volume $V^{\mathrm{E}}$ deviation in isentropic compressibility $\Delta \kappa_{s}$ and deviation in viscosity $\Delta \eta$ are calculated. These results have been fitted to the Redlich-Kister polynomial equation [16] to estimate the binary coefficients and the standard deviation between experimental and calculated data. Results have been used to explain the nature of intermolecular interactions between mixing components.

\section{Experimental}

Chemicals

$N, N$-diethylaniline $99.7 \%$ of purity, acetophenone $>99 \%$ of purity, cyclopentanone $99.1 \%$ of purity, cyclohexanone $>99 \%$ of purity, and 2-methylcyclohexanone $>99 \%$ of purity were purchased from Merck, S.D. Fine Chemicals Ltd., India. All samples were used without further purification because their purities exceeded $99.0 \%$ as tested by gas chromatography using a flame ionization detector with a packed column. Experimental values such as densities $\rho$, viscosities $\eta$, and ultrasonic speeds $u$ of the pure liquids are compared with the literature values [7, 17-21] in Table 1 at $298.15 \mathrm{~K}$, and the values are in good agreement.

Apparatus and procedure

The binary mixtures of $\mathrm{N}, \mathrm{N}$-diethylaniline with acetophenone, cyclopentanone, cyclohexanone, and 2-methylcyclohexanone were prepared in glass bottles with air-tight stoppers, and adequate precautions were taken to minimize losses through evaporation. The weighing of solutions was made using Acculab ALC-210.4 digital electronic balance with a precision of $\pm 0.1 \mathrm{mg}$. The uncertainty in solution composition expressed in mole fraction was found to be less than $1 \times 10^{-4}$. After mixing the sample, the bubblefree homogeneous sample was transferred into the U-tube of the densimeter using a syringe. The density measurements were performed with a Rudolph Research Analytical digital densimeter (DDH-2911 Model), equipped with a built-in solid-state thermostat and a resident program with temperature of $(303.15$ and 308.15$) \mathrm{K} \pm 0.03 \mathrm{~K}$. The estimated accuracy in the density measurement is $\pm 2 \times 10^{-5} \mathrm{~g} \mathrm{~cm}^{-3}$. Proper calibration at each temperature was achieved with doubly distilled, deionized water and with air as standards. A multi-frequency ultrasonic interferometer (M-82 Model, Mittal Enterprise, New Delhi, India) operated at $2 \mathrm{MHz}$ was used to measure the ultrasonic velocities in binary liquid mixtures at constant temperature of (303.15 and 308.15) K controlled by a digital constant temperature water bath. The uncertainty in the measurement of ultrasonic sound velocity is $\pm 0.2 \%$.

The viscosities of pure liquids and their mixtures were determined at atmospheric pressure and at temperature $303.15 \mathrm{~K}$ using an Ubbelohde viscometer, which was 
calibrated with benzene and doubly distilled water. The Ubbelohde viscometer bulb has a capacity of $15 \mathrm{~mL}$ and a capillary tube with a length of about $90 \mathrm{~mm}$ with $0.5 \mathrm{~mm}$ internal diameter. The viscometer, thoroughly cleaned and perfectly dried, was filled with the sample liquid by fitting the viscometer to about $30^{\circ}$ from the vertical and its limbs were closed with Teflon caps to avoid the evaporation. The viscometer was kept in a transparent walled bath with a thermal stability of $\pm 0.01 \mathrm{~K}$ for about $20 \mathrm{~min}$ to obtain thermal equilibrium. An electronic digital stopwatch with an uncertainty $\pm 0.01 \mathrm{~s}$ was used for flow time measurements. The viscosity values of pure liquids and mixtures are calculated using the relation

$\eta=(a t-b / t) \rho$

where $a$ and $b$ are the characteristic constants of the viscometer, $\rho$ is the density, and $t$ represents the flow time. The uncertainty of viscosity thus estimated was found to be $\pm 0.005 \mathrm{mPa} . \mathrm{s}$.

\section{Results and discussion}

The experimental values of density $\rho$, viscosity $\eta$, and ultrasonic velocity $u$ of pure liquids and their mixtures as function of mole fraction of $N, N$-diethylaniline at (303.15 and 308.15) $\mathrm{K}$ were used to calculate the parameters such as $V^{\mathrm{E}}, \kappa_{\mathrm{s}}, \Delta \kappa_{s}$, and $\Delta \eta$ from experimental data using the following expressions:

$$
\begin{aligned}
& V^{\mathrm{E}}=\left[x_{1} M_{1}+x_{2} M_{2}\right] / \rho_{\mathrm{m}}-\left[x_{1} M_{1} / \rho_{1}+x_{2} M_{2} / \rho_{2}\right] \\
& \Delta \mathrm{u}=\mathrm{U}-\left[\mathrm{X}_{1} \mathrm{U}_{1}+\mathrm{X}_{2} \mathrm{U}_{2}\right] \\
& \Delta \kappa_{s}=\kappa_{s}-\left[x_{1} \kappa_{s 1}+x_{2} \kappa_{s 2}\right] \\
& \Delta \eta=\eta-\left[x_{1} \eta_{1}+x_{2} \eta_{2}\right]
\end{aligned}
$$

In the above equations, $M_{1}, M_{2}, \kappa_{\mathrm{s} 1}, \kappa_{\mathrm{s} 2}, \eta_{1}, \eta_{2}, u_{1}, u_{2}$, $\rho_{1}, \rho_{2}, \rho_{\mathrm{m}}, \kappa_{\mathrm{s}}, \eta$, and $u$ represent molecular mass, isentropic compressibility, viscosity, ultrasonic sound velocity, and density data of component 1 , component 2 , the and mixture, respectively.

The data related to excess volume $\left(V^{\mathrm{E}}\right)$, deviation in isentropic compressibility $\left(\Delta \kappa_{\mathrm{s}}\right)$, and deviation in viscosity $(\Delta \eta)$ for the binary systems of $N, N$-diethylaniline with acetophenone, cyclopentanone, cyclohexanone, and 2-methycyclohexanone are graphically represented in Figs. 1, 2, and 3, respectively, at (303.15 and 308.15) K.

An examination of curves in Fig. 1 suggests that the $V^{\mathrm{E}}$ data for $N, N$-diethylaniline with cyclohexanone and +2 methylcylohexanone are positive over the entire composition range, and for mixtures of $N, N$-diethylaniline with acetophenone and cyclopentanone, the property is negative. The excess volume $\left(V^{\mathrm{E}}\right)$ for the above-mentioned systems is the resultant contribution from several opposing effects, namely, chemical, physical, and structural. The chemical or specific interactions result in volume contractions, leading to negative excess volume and these include charge-transfer complexes, dipole-dipole and dipole-induced dipole interactions, and $\mathrm{H}$-bonding between component molecules. Further, the structural contributions are mostly negative and arise from several effects such as interstitial accommodation and geometrical fitting of one component into another due to the differences in the molar volume and free volume between components. The physical interactions or non-specific interactions are weak, contributing positive $V^{\mathrm{E}}$.

A perusal of curves in Fig. 1 indicates that the factors which are responsible for negative excess volume were dominant in the binary mixtures of $N, N$-diethylaniline with acetophenone and cyclopentanone. On the other hand, the property is positive in the binary mixtures containing cyclohexanone and 2-methylcyclohexanone.

The negative values of $V^{\mathrm{E}}$ of binary mixtures of $N, N$ diethylaniline with ketones may be attributed to the dipoledipole interactions resulting in the formation of electrontransfer complexes between ketones and $\pi$-electron cloud of $N, N$-diethylaniline. Nitrogen atoms are the best donors [22] possessing lone pairs of electrons on them. Hence, $\mathrm{N}, \mathrm{N}$ diethylaniline is a good electron pair donor to exhibit specific interactions between them. This type of similar trend was observed for high polar solvent of $N, N$-dimethylformamide with ketones [23]. Further, the positive values for the systems containing cyclohexanone and 2-methylcyclohexanone in the present study suggest that there is no existence of specific interactions between unlike molecules [24].

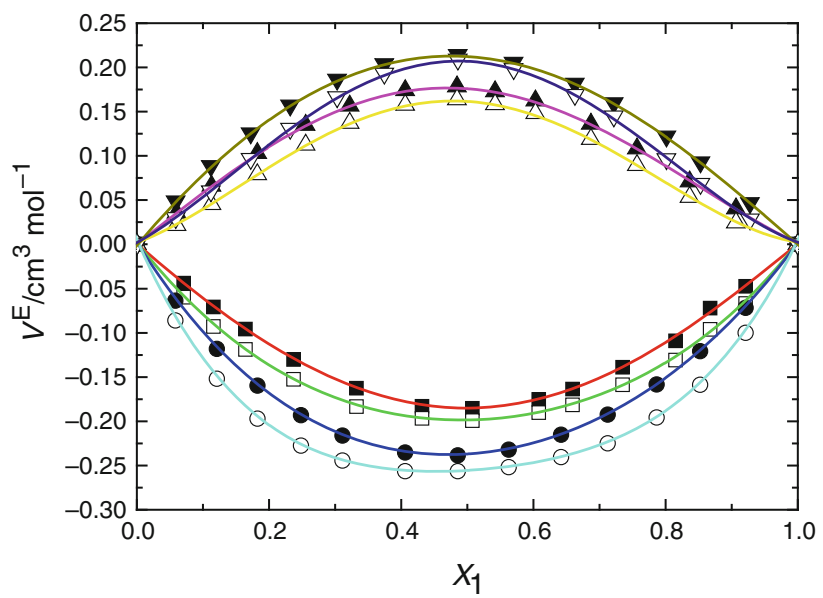

Fig. 1 Variation of $V^{\mathrm{E}}$ of the binary liquid mixtures of $N, N$ diethylaniline with acetophenone (filled square), cyclopentanone (filled circle), cyclohexanone (filled triangle), 2-methylcyclohexanone (filled inverted triangle) at $303.15 \mathrm{~K}$ and acetophenone (open square), cyclopentanone (open circle), cyclohexanone (open triangle), 2-methylcyclohexanone (open inverted triangle) at $308.15 \mathrm{~K}$ 
The negative excess volume data for the binary mixture of $\mathrm{N}, \mathrm{N}$-diethylaniline with acetophenone is less compared to cyclopentanone. This reflects that when both component molecules have the same ring size, weak dipole-dipole interactions can be expected.

The negative $V^{\mathrm{E}}$ value for the system $N, N$-diethylaniline with cyclopentanone may be due to the difference between molecular size of $N, N$-diethylaniline (molar volume $=$ $161.3 \mathrm{~cm}^{3} \mathrm{~mol}^{-1}$ ) and cyclopentanone (molar volume = $89.61 \mathrm{~cm}^{3} \mathrm{~mol}^{-1}$ ) which might allow the favorable fitting of smaller cyclopentanone molecules into voids present in the bigger $N, N$-diethylaniline [25]. The positive $V^{\mathrm{E}}$ values for systems of $N, N$-diethylaniline with cyclohexanone and +2 methylcyclohexanone may be due to the effect of a larger ring size of cyclic ketones. As the ring size of cyclic ketones increases, which in turn increases their polarizability, repulsive forces also increase, causing the $V^{\mathrm{E}}$ positive. The positive $V^{\mathrm{E}}$ value of the $N, N$-diethylaniline with 2-methylcyclohexanone is larger than that of cyclohexanone due to the positive inductive effect of the methyl group in 2-methylcyclohexanone, resulting in decreased polarizability.

The algebraic $V^{\mathrm{E}}$ values of $N, N$-diethylaniline with cyclic ketones follow the order

\section{$\mathrm{CP}<\mathrm{CH}<2-\mathrm{Me}-\mathrm{CH}$}

An examination of curves in Fig. 2 reveals that a deviation in isentropic compressibility $\left(\Delta \kappa_{s}\right)$ is negative for the binary mixtures $N, N$-diethylaniline with acetophenone and cyclopentanone, while it is positive for mixtures containing cyclohexanone and 2-methylcyclohexanone over the entire range of composition at both the temperatures. The $\Delta \kappa_{s}$ values

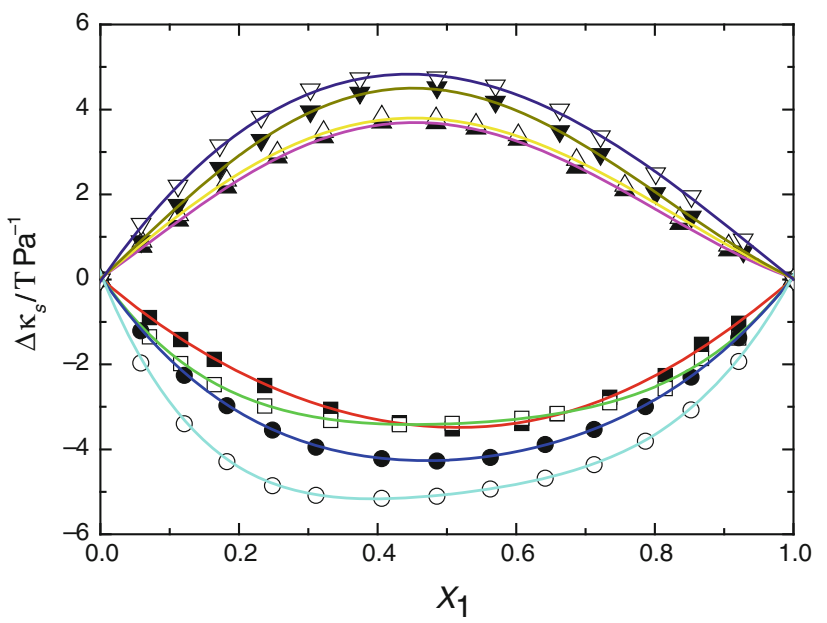

Fig. 2 Variation of $\Delta \kappa_{s}$ of the binary liquid mixtures of $\mathrm{N}, \mathrm{N}$ diethylaniline with acetophenone, (filled square), cyclopentanone (filled circle), cyclohexanone (filled triangle), 2-methylcyclohexanone (filled inverted triangle) at $303.15 \mathrm{~K}$ and acetophenone (open square), cyclopentanone (open circle), cyclohexanone (open triangle), 2-methylcyclohexanone (open inverted triangle) at $308.15 \mathrm{~K}$ were ascribed according to Sri Devi et al. [26]; the negative excess values have been due to the closely packed molecules which account for the existence of strong molecular interaction, whereas positive excess values are caused by dispersion forces between unlike molecules. The sign of deviation in isentropic compressibility $\left(\Delta \kappa_{s}\right)$ plays a vital role in assessing the compactness due to molecular interaction in liquid mixtures through hydrogen bonding, charge-transfer complex formation, dipole-dipole interactions and dipoleinduced dipole interactions, interstitial accommodation, and orientational order [27] leading to more compact structure making negative deviation in isentropic compressibility. The positive $\Delta \kappa_{s}$ values for $N, N$-diethylaniline with cyclohexanone and 2-methyl cyclohexanone may be attributed to the loss of dipole association [28] and difference in size, shape, and mass of the unlike component molecules in the mixtures, and the negative $\Delta \kappa_{s}$ values for $N, N$-diethylaniline with acetophenone and cyclopentanone may be attributed to the dipole-dipole interactions resulting in the formation of electron-transfer complexes between unlike molecules.

The algebraic $\Delta \kappa_{s}$ values of $N, N$-diethylaniline with acetophenone and cyclic ketones follow the order

$\mathrm{CP}<\mathrm{AP}<\mathrm{CH}<2-\mathrm{Me}-\mathrm{CH}$

According to Fort and Moore [27], deviation in viscosity tends to become more positive as the strength of the interaction between component molecules increases. The deviation in viscosity gives a qualitative estimation of the strength of the intermolecular interactions. It may be generally explained by considering the following factors. (i) The difference in size and shape of the component

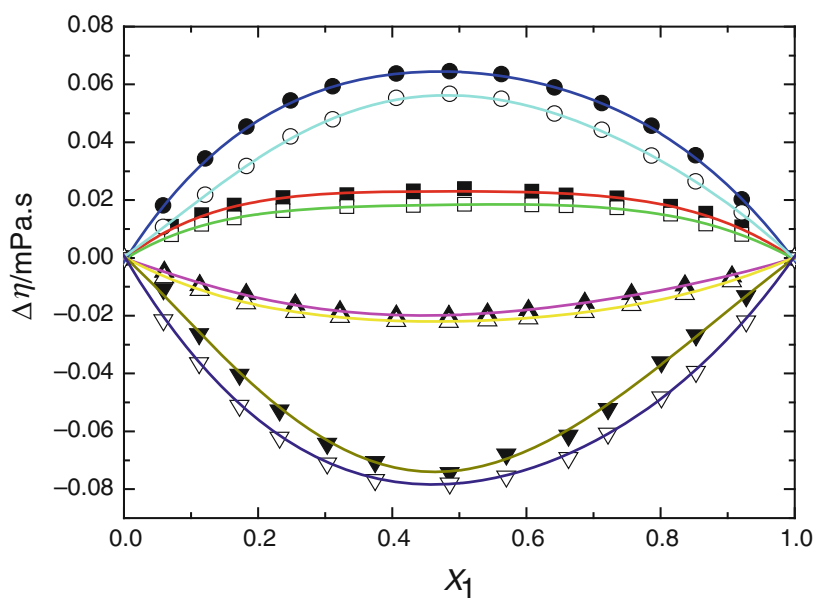

Fig. 3 Variation of $\Delta \eta$ of the binary liquid mixtures of $\mathrm{N}, \mathrm{N}$ diethylaniline with acetophenone (filled square), cyclopentanone (filled circle), cyclohexanone (filled triangle), 2-methylcyclohexanone (filled inverted triangle) at $303.15 \mathrm{~K}$ and acetophenone (open square), cyclopentanone (open circle), cyclohexanone (open triangle), 2-methylcyclohexanone (open inverted triangle) at $308.15 \mathrm{~K}$ 
Table 2 Coefficients of Redlich-Kister equation and standard deviation values at 303.15 and $308.15 \mathrm{~K}$

\begin{tabular}{|c|c|c|c|c|c|c|}
\hline Binary mixtures & $\mathrm{T} / \mathrm{K}$ & Functions & $a_{0}$ & $a_{1}$ & $a_{2}$ & $\sigma$ \\
\hline \multirow[t]{3}{*}{$N, N$-diethylaniline + acetophenone } & \multirow[t]{3}{*}{303.15} & $V^{\mathrm{E}} / \mathrm{cm}^{3} \mathrm{~mol}^{-1}$ & -0.951 & 0.091 & -0.158 & 0.001 \\
\hline & & $\Delta \kappa_{\mathrm{s}} / \mathrm{TPa}^{-1}$ & -17.12 & 1.588 & -4.617 & 0.016 \\
\hline & & $\Delta \eta / \mathrm{mPa} . \mathrm{s}$ & 0.261 & -0.024 & 0.056 & 0.001 \\
\hline \multirow[t]{3}{*}{$N, N$-diethylaniline + cyclopentanone } & \multirow[t]{3}{*}{303.15} & $V^{\mathrm{E}} / \mathrm{cm}^{3} \mathrm{~mol}^{-1}$ & 0.707 & -0.112 & -0.227 & 0.001 \\
\hline & & $\Delta \kappa_{\mathrm{s}} / \mathrm{TPa}^{-1}$ & 14.66 & -3.593 & -5.719 & 0.027 \\
\hline & & $\Delta \eta / \mathrm{mPa} . \mathrm{s}$ & -0.078 & 0.012 & -0.002 & 0.001 \\
\hline \multirow[t]{3}{*}{$\mathrm{N}, \mathrm{N}$-diethylaniline + cyclohexanone } & \multirow[t]{3}{*}{303.15} & $V^{\mathrm{E}} / \mathrm{cm}^{3} \mathrm{~mol}^{-1}$ & 0.854 & -0.104 & -0.084 & 0.001 \\
\hline & & $\Delta \kappa_{\mathrm{s}} / \mathrm{TPa}^{-1}$ & 17.92 & -4.338 & -6.459 & 0.033 \\
\hline & & $\Delta \eta / \mathrm{mPa} . \mathrm{s}$ & -0.300 & 0.032 & 0.126 & 0.002 \\
\hline \multirow[t]{3}{*}{$N, N$-diethylaniline +2 -methylcyclohexanone } & \multirow[t]{3}{*}{303.15} & $V^{\mathrm{E}} / \mathrm{cm}^{3} \mathrm{~mol}^{-1}$ & -0.793 & 0.003 & -0.169 & 0.002 \\
\hline & & $\Delta \kappa_{\mathrm{s}} / \mathrm{TPa}^{-1}$ & -13.58 & 0.954 & -8.462 & 0.023 \\
\hline & & $\Delta \eta / \mathrm{mPa} . \mathrm{s}$ & 0.071 & -0.006 & 0.072 & 0.001 \\
\hline \multirow[t]{3}{*}{$N, N$-diethylaniline + acetophenone } & \multirow[t]{3}{*}{308.15} & $V^{\mathrm{E}} / \mathrm{cm}^{3} \mathrm{~mol}^{-1}$ & -1.024 & 0.083 & -0.598 & 0.001 \\
\hline & & $\Delta \kappa_{\mathrm{s}} / \mathrm{TPa}^{-1}$ & -20.26 & 4.319 & -14.64 & 0.034 \\
\hline & & $\Delta \eta / \mathrm{mPa} . \mathrm{s}$ & 0.224 & 0.001 & -0.025 & 0.001 \\
\hline \multirow[t]{3}{*}{$N, N$-diethylaniline + cyclopentanone } & \multirow[t]{3}{*}{308.15} & $V^{\mathrm{E}} / \mathrm{cm}^{3} \mathrm{~mol}^{-1}$ & 0.652 & -0.087 & -0.448 & 0.001 \\
\hline & & $\Delta \kappa_{\mathrm{s}} / \mathrm{TPa}^{-1}$ & 15.04 & -3.733 & -4.082 & 0.033 \\
\hline & & $\Delta \eta / \mathrm{mPa} . \mathrm{s}$ & -0.088 & 0.011 & -0.027 & 0.001 \\
\hline \multirow[t]{3}{*}{$N, N$-diethylaniline + cyclohexanone } & \multirow[t]{3}{*}{308.15} & $V^{\mathrm{E}} / \mathrm{cm}^{3} \mathrm{~mol}^{-1}$ & 0.833 & -0.076 & -0.473 & 0.001 \\
\hline & & $\Delta \kappa_{\mathrm{s}} / \mathrm{TPa}^{-1}$ & 19.16 & -5.007 & -0.762 & 0.050 \\
\hline & & $\Delta \eta / \mathrm{mPa} . \mathrm{s}$ & -0.313 & 0.034 & -0.047 & 0.001 \\
\hline \multirow[t]{3}{*}{$N, N$-diethylaniline +2 -methylcyclohexanone } & \multirow[t]{3}{*}{308.15} & $V^{\mathrm{E}} / \mathrm{cm}^{3} \mathrm{~mol}^{-1}$ & -0.951 & 0.091 & -0.158 & 0.001 \\
\hline & & $\Delta \kappa_{\mathrm{s}} / \mathrm{TPa}^{-1}$ & -17.12 & 1.588 & -4.617 & 0.016 \\
\hline & & $\Delta \eta / \mathrm{mPa} . \mathrm{s}$ & 0.261 & -0.024 & 0.056 & 0.001 \\
\hline
\end{tabular}

molecules and the loss of dipolar association in a pure component may contribute to a decrease in viscosity, and (ii) specific interactions between unlike components such as hydrogen bond formation and charge-transfer complexes may cause increase in viscosity in mixtures compared to in pure components. The former effect produces negative deviation in viscosity and the latter effect produces positive deviation in viscosity.

An examination of curves in Fig. 3 shows that a deviation in viscosity $(\Delta \eta)$ data is positive for mixtures of $N, N$ diethylaniline with acetophenone and cyclopentanone and is negative for the systems containing cyclohexanone and 2-methylcyclohexanone over the entire composition ranges at (303.15 and 308.15) $\mathrm{K}$.

The excess Gibbs free energy of activation of viscous flow $\left(G^{*} \mathrm{E}\right)$ is obtained by the equation

$G^{* \mathrm{E}}=R T\left[\ln \eta V-\left(x_{1} \ln \eta_{1} V_{1}+x_{2} \ln \eta_{2} V_{2}\right)\right]$

where $V_{1}, V_{2}$, and $V$ are the molar volumes of the component 1 and component 2 and molar volume of the mixture, respectively; $R$ and $T$ have their usual meanings.

Grunberg and Nissan [28] proposed the following equation for the measurement of viscosity of liquid mixtures: $\ln \eta=x_{1} \ln \eta_{1}+x_{2} \ln \eta_{2}+x_{1} x_{2} d_{12}$

where $d_{12}$ is a parameter proportional to interchange energy, which reflects the non-ideality of the system.

Katti and Chaudhri [29] proposed the following equation:

$\ln \eta V=x_{1} \ln V_{1} \eta_{1}+x_{2} \ln V_{2} \eta_{2}+x_{1} x_{2} W_{\text {vis }} / R T$

where $W_{\text {vis }} / R T$ is an interaction term.

Hind et al. [30] suggested an equation for the viscosity of binary liquid mixtures as

$\eta=x_{1}^{2} \eta_{1}+x_{2}^{2} \eta_{2}+2 x_{1} x_{2} H_{12}$

where $H_{12}$ is the Hind interaction parameter, and the above-mentioned computed values are also presented in Table 2.

The positive $\Delta \eta$ values indicate the existence of specific interactions between component molecules [31-34], while the negative $\Delta \eta$ values suggest that dispersion forces are dominant in mixtures. The existence of dispersion forces indicates that the component molecules have different molecular sizes and shapes [35].

Attempts [28, 32, 36] have been made to explain the behavior of liquid mixtures on the basis of the sign and magnitude of deviation in viscosity $\Delta \eta$, excess molar Gibbs 
free energy of activation of flow $\left(G^{*} \mathrm{E}\right)$, and Nissan's parameter $d_{12}$. In the present investigation, the values of $G^{*} \mathrm{E}$ and $\mathrm{d}_{12}$ are positive for $N, N$-diethylaniline with acetophenone, cyclopentanone, and cyclohexanone and are negative for $N, N$-diethylaniline with 2-methylcyclohexanone. The positive values of $G^{* \mathrm{E}}$ and $\mathrm{d}_{12}$ are due to the presence of strong specific interactions between component molecules, whereas their negative values suggest the existence of weaker interaction [32].

The variation of $V^{\mathrm{E}}, \Delta \kappa_{s}$, and $\Delta \eta$ with mole fraction was fitted to the Redlich-Kister polynomial equation [16] of the type

$Y^{\mathrm{E}}=x_{1} x_{2}\left[a_{0}+a_{1}\left(x_{1}-x_{2}\right)+a_{2}\left(x_{1}-x_{2}\right)^{2}\right]$

where $Y^{\mathrm{E}}$ is $V^{\mathrm{E}}$ or $\Delta \kappa_{s}$ or $\Delta \eta$. The values of $a_{0}, a_{1}$, and $a_{2}$ are the coefficients of the polynomial equation, and the corresponding standard deviations $\sigma$ obtained by the method of least squares with equal masses assigned to each point are calculated. The standard deviation $(\sigma)$ is defined as

$\sigma\left(Y^{\mathrm{E}}\right)=\left[\sum\left(Y_{\mathrm{obs}}^{\mathrm{E}}-Y_{\mathrm{cal}}^{\mathrm{E}}\right)^{2} /(n-m)\right]^{1 / 2}$

where $n$ is the total number of experimental points and $m$ is the number of coefficients. The values of $a_{0}, a_{1}$, and $a_{2}$ are the coefficients determined by a multiple-regression analysis on the least square method and summarized along with the standard deviations between the experimental and fitted values of $V^{\mathrm{E}}, \Delta \kappa_{s}$, and $\Delta \eta$, presented in Table 2. Finally, it can be concluded that the expressions used for interpolating the experimental data measured in this work show good results as can be seen by inspecting the $\sigma$ values obtained.

\section{Conclusions}

The experimental values of density, viscosity, and speed of sound for the binary mixtures of $N, N$-diethylaniline with acetophenone, cyclopentanone, cyclohexanone, and 2-methylcyclohexanone at (303.15 and 308.15) $\mathrm{K}$ and different compositions are measured. From these data, several thermodynamic excess functions have been calculated and correlated using the Redlich-Kister-type polynomial equation. The sign and magnitude of these quantities have been discussed in terms of electron-transfer complexes and dipole-dipole interactions between the mixing components.

Acknowledgements The author M.Gowrisankar is thankful to the University Grants Commission (UGC), New Delhi, India, for providing a Teacher Fellowship and expresses gratitude to the Management and Principal, J.K.C. College, Guntur-522006.
Open Access This article is distributed under the terms of the Creative Commons Attribution License which permits any use, distribution, and reproduction in any medium, provided the original author(s) and the source are credited.

\section{References}

1. Gowri sankar M, Sivarambabu S, Venkateswarlu P, Siva kumar $\mathrm{K}$. Excess volumes, speeds of sound, isentropic compressibilities and viscosities of binary mixtures of $N$-ethyl aniline with some aromatic ketones at 303.15 K. Bull Korean Chem Soc. 2012; 33:1686-92.

2. Gowri sankar M, Venkateswarlu P, Siva kumar K, Sivarambabu $\mathrm{S}$. Thermodynamics of amine + ketone mixtures 3. Volumetric, speed of sound data and viscosity at $(303.15$ and $308.15 \mathrm{~K})$ for the binary mixtures of $\mathrm{N}, \mathrm{N}$-dimethylaniline + propiophenone, + p-methylacetophenone, + p-chloroacetophenone. J Mol Liq. 2012;173:172-9.

3. Gowri sankar M, Venkateswarlu P, Siva kumar K, Sivarambabu S. Ultrasonic studies on molecular interactions in binary mixtures of $N$-methyl aniline with methyl isobutylketone, +3 -pentanone, +cycloalkanones at 303.15 K. J Soln Chem. 2013;42(5):916-35.

4. Gowri sankar M, Venkateswarlu P, Siva kumar K, Sivarambabu S. Density, ultrasonic velocity, viscosity and their excess parameters of the binary mixtures of $\mathrm{N}, \mathrm{N}$-dimethylaniline with 1-alkanols $\left(\mathrm{C}_{3}-\mathrm{C}_{5}\right)$, +2-alkanols $\left(\mathrm{C}_{3}-\mathrm{C}_{4}\right)$, +2-methyl-1-propanol, +2-methyl-2-propanol at $303.15 \mathrm{~K}$. Korean J Chem Eng. 2013;30(5):1131-41.

5. Kondaiah M, Sravana KD, Sreekanth K, Krishna RD. Densities and viscosities of binary mixtures of propanoic acid with $\mathrm{N}, \mathrm{N}$ dimethylaniline and $N, N$-diethylaniline at (303.15, 313.15, 323.15) K. J Chem Eng Data. 2012;57:352-7.

6. Kumar H, Kaur M, Gaba R, Kaur K. Thermodynamics of binary liquid mixtures of cyclopentane with 2-propanol, 1-butanol and 2-butanol at different temperatures. J Therm Anal Calorim. 2011:105:1071-80.

7. Comelli F, Francesconi R. Densities and excess molar volumes of propylene carbonate + linear and cyclic ketones at $298.15 \mathrm{~K}$. J Chem Eng Data. 1995;40:808-10.

8. Comelli F, Francesconi R. Densities and Excess molar volumes of binary mixtures of containing diethyl carbonate + linear and cyclic ketones at 298.15 K. J Chem Eng Data. 1995;40:25-7.

9. Pandiyan V, Oswal SL, Vasantharani P. Thermodynamic and acoustic properties of binary mixtures of ethers. IV. Diisopropyl ether or oxolane with $\mathrm{N}, \mathrm{N}$-dimethylaniline or $\mathrm{N}, \mathrm{N}$-diethylaniline at $303.15,313.15$ and $323.15 \mathrm{~K}$. Thermochim Acta. 2011;518: $36-46$.

10. Kinart CM, Kinart WJ, Cwiklinska A. 2-Methoxyethanol-tetrahydrofuran binary liquid system viscosities, densities, excess molar volumes and excess Gibbs activation energies of viscous flow at various temperatures. J Therm Anal Calorim. 2002;68: $307-8$.

11. Bartłomiej P, Agnieszka S. Study of the interaction between ethanol and natural amino acids containing ionic side groups in water at $T=298.15 \mathrm{~K}$. J Therm Anal Calorim. 2013;111: 917-21.

12. Bracos P, Pineiro A, Bravo R, Amigo A, Roux AH, Roux-Desgtanges $\mathrm{G}$. Thermodynamics of mixtures involving some linear cyclic ketones and cyclic ethers. 4. systems containing 1,3dioxane. J Chem Eng Data. 2004;49:647-57.

13. Sreekanth K, Kondaiah M, Sravana Kumar D, Rao Krishna D. Influence of temperature on thermodynamic properties of acidbase liquid mixtures. J Therm Anal Calorim. 2012;110:1341-52. 
14. Zeng Ju-Lan, Yu Sai-Bo, Tong Bo, Sun Li-Xian, Tan Zhi-Cheng, Cao Zhong, Yang Dao-Wu, Zhang Jing-Nan. Heat capacities and thermodynamic properties of (S)-tert-butyl1-phenylethylcarbamate. J Therm Anal Calorim. 2011;103:1087-93.

15. Cibulka I, Simurka L, Hnedkovsky L, Bolotov A. Partial molar volumes of organic solutes in water. XXIII. Cyclic ketones at $\mathrm{T}=(298$ to 573$) \mathrm{K}$ and pressures up to $30 \mathrm{MPa}$. J Chem Eng Data. 2011;43:1028-35.

16. Redlich O, Kister AT. Thermodynamics of non electrolytic solutions. Algebraic representation of Thermodynamic properties and the classification of solutions. Ind Eng Chem. 1948;40:345-8.

17. Palepu R, Joan O, Campell D. Thermodynamic and transport properties of $O$-chlorophenol with aniline and $\mathrm{N}$-alkyl anilines. J Chem Eng Data. 1985;30:355-60.

18. Oswal SL, Pandiyan V, Krishnakumar B, Vasantharani P. Thermodynamic and acoustic properties of binary mixtures of oxolane with aniline and substituted anilines at 303.15, 313.15 and 323.15 K. Thermochim Acta. 2010;2010(507):27-34.

19. Rathnam MV, Reema T, Sayed T, Kavita RB, Kumar MSS. Density and viscosity of binary mixtures of n-butyl acetate with ketones at $(298.15,303.15,308.15$ and 313.15) K. J Chem Eng Data. 2012;57:1721-7.

20. Rajagopal K, Chenthilnath S. Excess thermodynamic studies of binary mixtures of 2-methyl-2-propanol with ketones. Indian $\mathrm{J}$ Pure Appl Phys. 2010;48:326-33.

21. Dharmaraju G, Narayanaswamy G, Raman GK. Excess volumes and isentropic compressibilities of binary mixtures of a ketone and acetonitrile. J Chem Eng Data. 1982;27:193-5.

22. Krishnaiah A, Rao DN, Naidu PR. Ultrasonic Studies of binary mixtures of chlorobenzene with Acetonitrile and Propionitrile. Indian J. Chem. 1982;21 A:290-2.

23. Venkatesu P, Rao MVP. Excess volumes of $N, N$-dimethylformamide with ketones at 303.15 K. J Chem Eng Data. 1996;41: 1059-60.

24. Chawla B, Mehta SK, Jasra RV, Suri SK. Excess volumes of binary mixtures of cyclohexanone with some monosubstituted benzenes at 298.15 K. Can J Chem. 1983;61:2147-50.
25. Dernini S, Polcaro AM, Ricci PF. Thermodynamic properties of binary mixtures containing cycloalkanones: excess volumes of Cycloalkanones + cyclohexane, + benzene and + tetrachlormethane. J Chem Eng Data. 1989;34:165-7.

26. Sri Devi U, Samatha K, Visvanantasarma A. Excess thermodynamic properties in binary liquids. J Pure Appl Ultrason. 2004;26:1-11.

27. Fort RJ, Moore WR. Adiabatic compressibilities of binary liquids mixtures. Trans Faraday Soc. 1965;61:2102-11.

28. Grunberg L, Nissan AH. Mixture law for viscosity. Nature. 1949;164:799-800.

29. Katti PK, Chaudhri MH. Viscosities of binary mixtures benzyl acetate with dioxane, aniline and m-cresol. J Chem Eng Data. 1964;9:442-3.

30. Hind RK, McLaughlin E, Ubbelohde A. Structure and viscosity of liquid camphor and pyrene mixtures. Trans Faraday Soc. 1960;56:328-30.

31. Pikkarainan L. Densities and viscosities of binary mixtures of $N, N$-dimethylacetamide with aliphatic alcohols. J Chem Eng Data. 1983;28:344-7.

32. Fort RJ, Moore WR. Viscosities of binary liquid mixtures. Trans Faraday Soc. 1966;62:1112-9.

33. Palepu R, Oliver J, Mackinnon B. Viscosities and densities of binary liquid mixtures of $\mathrm{m}$-cresol with substituted aniline. Part 3 . Can J Chem. 1985;63:1024-30.

34. Reed TM III, Taylor TE. Viscosity of liquid mixtures. J Phys Chem. 1959;63:58-67.

35. Dubey GP, Sharma M, Dubey N. Study of molecular interactions in binary liquid mixtures of 1 -octanol with $n$-hexane, $n$-octane and $n$-decane using volumetric viscometric and acoustic properties. J Chem Thremodyn. 2008;40:999-1000.

36. Prakash S, Sivanarayana K, Prakash O. Thermodynamic and transport properties of binary liquid systems. Can J Chem. 1980;58:942-5. 